Stevenson, I. L. (1956). J. gen. Microbiol. 14, 440-448

\title{
Antibiotic Activity of Actinomycetes in Soil and their Controlling Effects on Root-rot of Wheat
}

\author{
By I. L. STEVENSON \\ Rothamsted Experimental Station, Harpenden, Hertfordshire and Bacteriology \\ Division, Science Service, Department of Agriculture, Ottawa, Canada
}

SUMMARY : A study has been made of conditions affecting the production of antibiotics in three soils by a number of unidentified Streptomyces spp. capable of inhibiting a variety of test organisms in vitro. In actinomycete-inoculated soils, antibiotic production was demonstrated only in sterile soils supplemented with a suitable organic source. The greatest accumulations of antibiotics were found in a neutral soil with added glucose $(2 \cdot 5 \%)$ while under similar conditions, no antibioties, or only traces were recovered from acid and alkaline soils. Antibiotics, however, could be recovered from inoculated acid soil, following neutralization and the addition of glucose. Fresh grass $(3 \%)$, clover $(3 \%)$ and soybean meal $(2 \%)$ were also suitable supplements for antibiotic production by the majority of the actinomycetes, though the amounts of antibiotics were considerably less than in glucose-treated soils.

In greenhouse experiments the assessment of root damage to wheat seedlings in sterile soil demonstrated that all the actinomycetes tested significantly reduced the degree of root-rot caused by Helminthosporium sativum. In the neutral and alkaline soils a relationship was evident between disease incidence and degree of antagonism exhibited by actinomycetes in vitro, suggesting that antibiotics were responsible. No such relationship was observed between disease control and the antibioticproducing abilities of the actinomycetes in soil as determined by standard assay procedures.

Numerous investigations have been undertaken in attempts to distinguish between the various types of actinomycete antagonisms occurring in soil. High percentages of actinomycete soil isolates have been found to produce antibiotics in vitro and it is conceivable that these substances may be formed in soil and play an active role in microbial antagonism (Landerkin, Smith \& Lochhead, 1950; Stevenson, 1953; Waksman, Horning, Welsch \& Woodruff, 1942). Some evidence has already accumulated, showing that many actinomycetes can produce detectable quantities of antibiotics in sterile, supplemented soils (Gottlieb \& Siminoff, 1952; Gregory, Allen, Riker \& Peterson, 1952); but evidence of antibiotic production in natural soils is still lacking.

Attempts to control root diseases by inoculation of the infested soils with actinomycete isolates have met with considerable success. Cooper \& Chilton (1947) tested various Streptomyces isolates and noted reduction of root-rot in sugar cane and corn plants infested with a Pythium sp. Other workers have noted similar disease control through the inoculation of antagonistic microorganisms into soil (Lachance \& Perrault, 1953; Slagg \& Fellows, 1947). It is difficult to decide from such experiments whether the observed antagonism is due to antibiotic production or to some other form of antagonism. 
Thaysen (1950) has emphasized the fact that although many microorganisms may be antagonistic to others in culture this is not indicative of antibiotic activity in soil. In this respect it is significant that several workers have reported a relationship between the antibiotic activity of microorganisms and their controlling effects on plant pathogenic fungi. Thus, Johnson (1952) was able to show that, with few exceptions, those actinomycete isolates which significantly reduced the root-rot of corn in soil were the most highly antagonistic on plates. Slagg \& Fellows (1947) found a number of soil fungi antagonistic to Ophiobolus in pure culture and, of a selected group of these, most were found to be antagonistic to the fungus in soil. Anwar (1949) emphasizes the importance of antibiotic-producing organisms in soil and reports the control of root-rot of barley by these antagonistic types.

This paper reports on results of a preliminary investigation concerned with the antagonistic relationships between ten antibiotic-producing actinomycetes and the root-rot fungus Helminthosporium sativum.

\section{METHODS}

The actinomycetes. The ten actinomycetes used throughout were all unidentified Streptomyces spp. Those referred to as D22, E4, E63, F19, XX19 and Y 27 were isolated by Landerkin et al. (1950) from the soils of northern Canada, while the actinomycetes AA24, AA27, AA30 and AA53 were isolated by Stevenson (1953) from soils of the Arno Atoll.

Determination of antibiotic activity. Antibiotic activity of the actinomycetes was determined by the cross-streak method against the following test organisms : Escherichia coli, Staphylococcus aureus, Bacillus subtilis, Helminthosporium sativum, Fusarium culmorum and Streptomyces scabies. The actinomycetes were streak-inoculated on plates of Conn's asparagine agar. After 5 days' incubation at $26^{\circ}$, the plates were flooded to the actinomycete growth with $3 \mathrm{ml}$. of a seeded agar medium suitable for the test organism. Plates were examined for antagonism after an appropriate incubation period and the inhibition zones measured.

Soils. Three contrasting soils were used, a highly acid ( $\mathrm{pH} 5 \cdot 0)$ sandy loam from Woburn, a medium loam soil ( $\mathrm{pH} \mathrm{6.9)}$ from the Highfield plots of the Rothamsted Experimental Station, and a Cotswold limestone soil ( $\mathrm{pH} \mathrm{8.0)} \mathrm{of}$ the Sherborne soil series. These are referred to as the acid, neutral and alkaline soils respectively. All soils were sieved and brought to $50 \%$ of their waterholding capacity. When sterilization was necessary the soils were autoclaved for $1 \mathrm{hr}$. at $15 \mathrm{lb} . / \mathrm{sq}$. in.

Inoculation of soils. Soil inocula were prepared in the following manner. Two ml. of a heavy aqueous suspension of actinomycete spores were added to test tubes containing $10 \mathrm{~g}$. of sterile, washed, white sand. The sand + spore mixtures were then added to flasks containing $100 \mathrm{~g}$. of the soil to be inoculated, and the whole shaken vigorously to ensure an even distribution of the spores throughout the soil.

Helminthosporium sativum soil inoculum was prepared in an identical manner. 
Extraction of antibiotics from soil. Preliminary experiments demonstrated that the antibiotics produced by the unknown actinomycetes were ether soluble at the $\mathrm{pH}$ values of the soils concerned. After incubation of the actinomyceteinoculated soils at $25^{\circ}$ for 14 days, the water content was estimated and appropriate quantities of the soils (5-25 g. dry weight) were extracted by vigorously shaking the soil for $10 \mathrm{~min}$. with three successive equivalent volumes of ether. The bulked extracts were concentrated in vacuo and assayed for antibiotic activity.

Antibiotic assay. A paper-disk assay method was adopted for assay of the ether extracts of soil. Extracts were added to thin blotting-paper disks $15 \mathrm{~mm}$. in diameter and dried at $37^{\circ}$ for $30 \mathrm{~min}$. The dried disks were then placed on plates seeded with Staphylococcus aureus, incubated for $24 \mathrm{hr}$. at $37^{\circ}$ and the diameters of the zones of inhibition measured and recorded in $\mathrm{mm}$. per given weight of soil.

Greenhouse studies. Three-inch clay pots with a capacity of $100 \mathrm{~g}$. were sterilized and half filled with sterile soil. Actinomycete and Helminthosporium sativum soil-inocula were prepared separately in flasks containing sterile soil with $2 \%$ soybean meal. After incubation, flasks of the fungal and actinomycete inocula were combined, and $50 \mathrm{~g}$. added to each pot. Check pots were also prepared with sterile and non-sterile soils containing the fungus only. The pots were then seeded with fourteen surface-sterilized wheat seeds and covered with a half inch layer of sterile soil.

Assessment of root-rot. The roots of wheat seedlings were carefully washed on removal from the pots and assessed for degree of root damage by a modification of the technique of McKinney (1923). The plants were separated into six classes according to degree of infection, and each plant given a numerical rating from 0 to 5 . A final infection rating for all plants grown in a given treatment was arrived at by the following equation:

$$
\frac{\text { sum of numerical ratings }}{\text { total no. of plants } \times 5} \times 100=\text { infection rating }(\%) \text {. }
$$

\section{RESULTS}

\section{Antibiotic spectra of the actinomycetes}

The range of antibiotic activity of the ten actinomycetes against a variety of test organisms in Petri dish culture is given in Table 1. In view of later experiments designed to determine the antagonism of these actinomycetes towards Helminthosporium sativum in soil, particular attention is drawn to the varying degrees by which this fungus is inhibited in vitro.

\section{Antibiotic production in soils}

Antibiotic production by the actinomycetes in variously treated acid, neutral, and alkaline soils was also determined. The recovery of antibiotics from sterile, supplemented soils inoculated with the actinomycetes are given in Table 2. 
In the neutral soil supplemented with $\mathbf{2 . 5} \%$ glucose, appreciable concentrations of antibiotics were produced by the actinomycetes AA 24, AA 27, D 22, E 4, E63 and F 19. In a similarly treated alkaline soil only small amounts of antibiotics were produced by four of these same actinomycetes. No antibiotics were detected in the supplemented acid soil.

Table 1. Antagonistic properties of actinomycetes in vitro

\begin{tabular}{|c|c|c|c|c|c|c|}
\hline \multirow{3}{*}{ Actinomycetes } & \multicolumn{6}{|c|}{ Test organisms } \\
\hline & S. aureus & B. subtilis & E. coli & S. scabies & H. sativum & F. culmorum \\
\hline & \multicolumn{6}{|c|}{ Zone widths in mm.; means of triplicate plates } \\
\hline AA 30 & 10 & 9 & 0 & 12 & 4 & 2 \\
\hline AA 53 & 26 & 21 & 23 & 17 & 10 & 3 \\
\hline D 22 & 24 & 21 & 0 & 15 & 12 & 8 \\
\hline E 4 & 33 & 25 & $\mathbf{0}$ & 19 & 15 & 10 \\
\hline F 19 & 27 & 21 & 0 & 15 & 15 & 9 \\
\hline E 63 & 34 & 25 & 0 & 17 & 18 & 12 \\
\hline AA 27 & 12 & 4 & 7 & 3 & 20 & 15 \\
\hline AA 24 & 22 & 5 & 13 & 4 & 22 & 18 \\
\hline Y 27 & 18 & 13 & 0 & 10 & 24 & 20 \\
\hline XX 19 & 17 & 12 & 0 & 2 & 24 & 20 \\
\hline
\end{tabular}

Further experiments were undertaken in which the glucose-supplemented acid and alkaline soils were neutralized by the addition of calcium hydroxide and hydrochloric acid respectively. Under these modified conditions actinomycete growth was evident in the acid soil and antibiotics were detected. Inasmuch as no antibiotics were detected in this soil previously, it is suggested that the low acid tolerance of the actinomycetes limited their activity in the soil. Neutralization of the alkaline soil did not improve antibiotic production by the actinomycetes.

Antibiotic production was also demonstrated in sterile, neutral and alkaline soils supplemented with such natural organic materials as fresh grass $(3 \%)$ and clover cuttings $(3 \%)$. Table 2 illustrates that the amounts of antibiotics detected were considerably smaller than those produced by some of the actinomycetes in the glucose-supplemented soils, but indicates that the majority of these organisms were capable of producing some antibiotic with these supplements.

The production of antibiotics in sterile soils supplemented with soybean meal was also determined. Soybean meal is the high protein, low carbohydrate remnants of soybeans after oil extraction: it was supplied by the British Oil Cake Mills Ltd., Erith, Kent. The amounts of antibiotic extracted under these conditions were of the same order as those found in the grass and clover-supplemented soils. The actinomycetes again failed to produce detectable quantities of antibiotics in the acid soil.

\section{Effects of actinomycetes on the incidence of root-rot of wheat}

The following studies were undertaken to determine the potential antagonism of the actinomycetes towards Helminthosporium sativum in the acid, neutral, and alkaline soils. In these experiments the degree of activity of the 


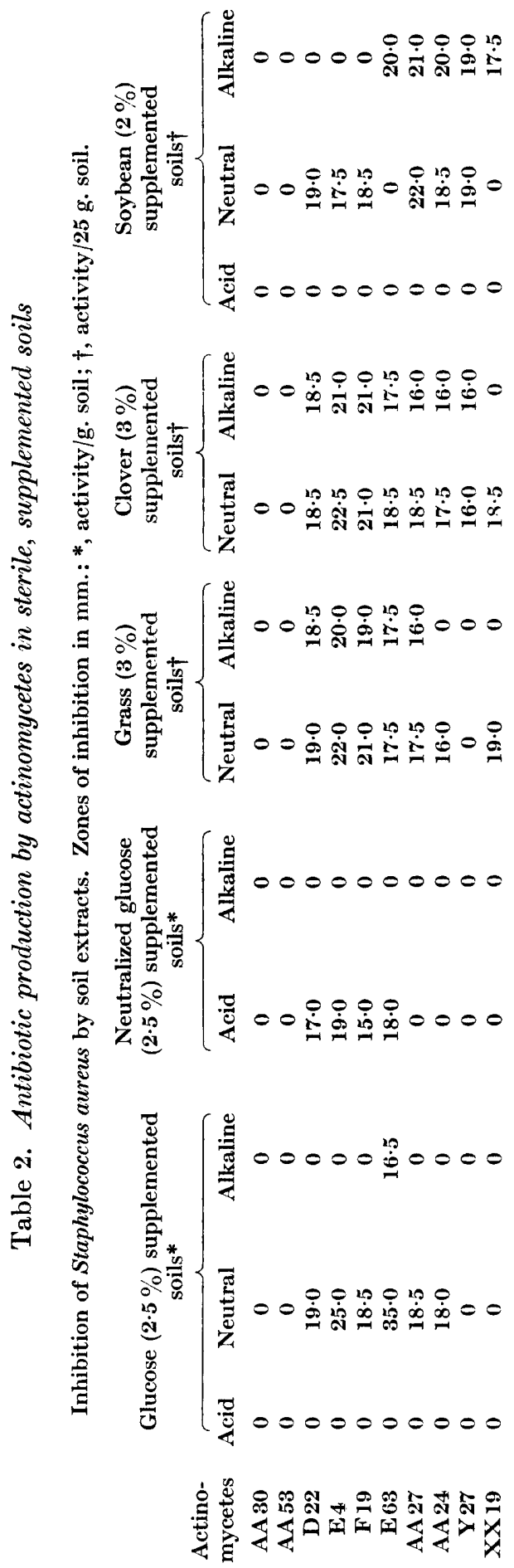


actinomycetes was measured in terms of their ability to reduce root-rot of wheat in soils inoculated with the fungus.

Twelve treatments were prepared in triplicate for each soil. Ten treatments consisted of a mixture of Helminthosporium sativum in combination with one of the ten actinomycetes in sterile soil. A treatment of $H$. sativum in nonsterile soil and control treatment of sterile soil plus $\boldsymbol{H}$. sativum were also prepared.

At the end of 60 days of growth, seedlings were removed from the pots, the degree of root-lesioning assessed, and the infection ratings calculated for each pot, treatment, and soil. To aid in the comparison of actinomycete effects between the different soils, the infection ratings were converted on the basis of the appropriate controls (sterile soil plus Helminthosporium sativum) being $100 \%$ infected. The average infection ratings for treatments and soils are given in Table 3.

Table 3. Average infection ratings of wheat seedlings (\%)

\begin{tabular}{|c|c|c|c|c|}
\hline & \multicolumn{3}{|c|}{ Soils } & \multirow{2}{*}{$\begin{array}{c}\text { In vitro } \\
\text { inhibition* }\end{array}$} \\
\hline & Acid & Neutral & Alkaline & \\
\hline $\begin{array}{l}\text { Sterile soil plus } \\
\text { H. sativum }\end{array}$ & $100 \cdot 0$ & $100 \cdot 0$ & $100 \cdot 0$ & - \\
\hline $\begin{array}{l}\text { Non-sterile soil plus } \\
\text { H. sativum }\end{array}$ & $47 \cdot 9$ & $31 \cdot 0$ & $29 \cdot 0$ & - \\
\hline AA 30 & $62 \cdot 6$ & $76 \cdot 5$ & $83 \cdot 5$ & 4 \\
\hline AA 53 & $62 \cdot 8$ & $83 \cdot 8$ & $82 \cdot 8$ & 10 \\
\hline D22 & $77 \cdot 4$ & $64 \cdot 0$ & $87 \cdot 6$ & 12 \\
\hline E.4 & $74 \cdot 4$ & $69 \cdot 9$ & $82 \cdot 5$ & 15 \\
\hline F 19 & $59 \cdot 4$ & $73 \cdot 2$ & $81 \cdot 0$ & 15 \\
\hline E63 & $73 \cdot 1$ & $60 \cdot 7$ & $74 \cdot 7$ & 18 \\
\hline AA 27 & $58 \cdot 9$ & $68 \cdot 8$ & $62 \cdot 9$ & 20 \\
\hline AA 24 & $62 \cdot 8$ & $47 \cdot 9$ & $61 \cdot 0$ & 22 \\
\hline Y 27 & $81 \cdot 5$ & $49 \cdot 2$ & $83 \cdot 8$ & 24 \\
\hline $\mathbf{X X 1 9}$ & $68 \cdot 2$ & $35 \cdot 5$ & $82 \cdot 9$ & 24 \\
\hline L.S.D. $†$ & $14 \cdot 5$ & $11 \cdot 9$ & $8 \cdot 7$ & - \\
\hline
\end{tabular}

Table 4. Analysis of variance of wheat infection ratings

\begin{tabular}{lcc}
\multicolumn{1}{c}{ Source } & D.F. & Mean squares \\
Treatments (T) & 11 & $\mathbf{7 4 4 \cdot 9 *}$ \\
Soils (S) & $\mathbf{2}$ & $\mathbf{7 7 9 \cdot 3 *}$ \\
$\mathrm{T} \times \mathrm{S}$ & $\mathbf{2 2}$ & $\mathbf{1 4 6 \cdot 8 *}$ \\
\multicolumn{3}{c}{ * Significant at $1 \%}$.
\end{tabular}

The analysis of variance of the data in Table 4 indicates that the actinomycete treatments and soils have both influenced the degree of root-rot of wheat. The least significant differences (Table 3) illustrate that all treatments have significantly reduced disease incidence in relation to the control treatments while the treatment-soil interaction of the analysis (Table 4) shows that the controlling effect of the individual treatments varies with the different soils. 
Inasmuch as all actinomycete treatments have reduced root-rot of wheat, the degree of control was compared with the ability of the individual actinomycetes to produce antibiotics in soil as well as with their in vitro inhibition of Helminthosporium sativum. Of the ten actinomycetes studied, D22, E4, E63 and F19 were the most consistent producers of antibiotics in the sterile-

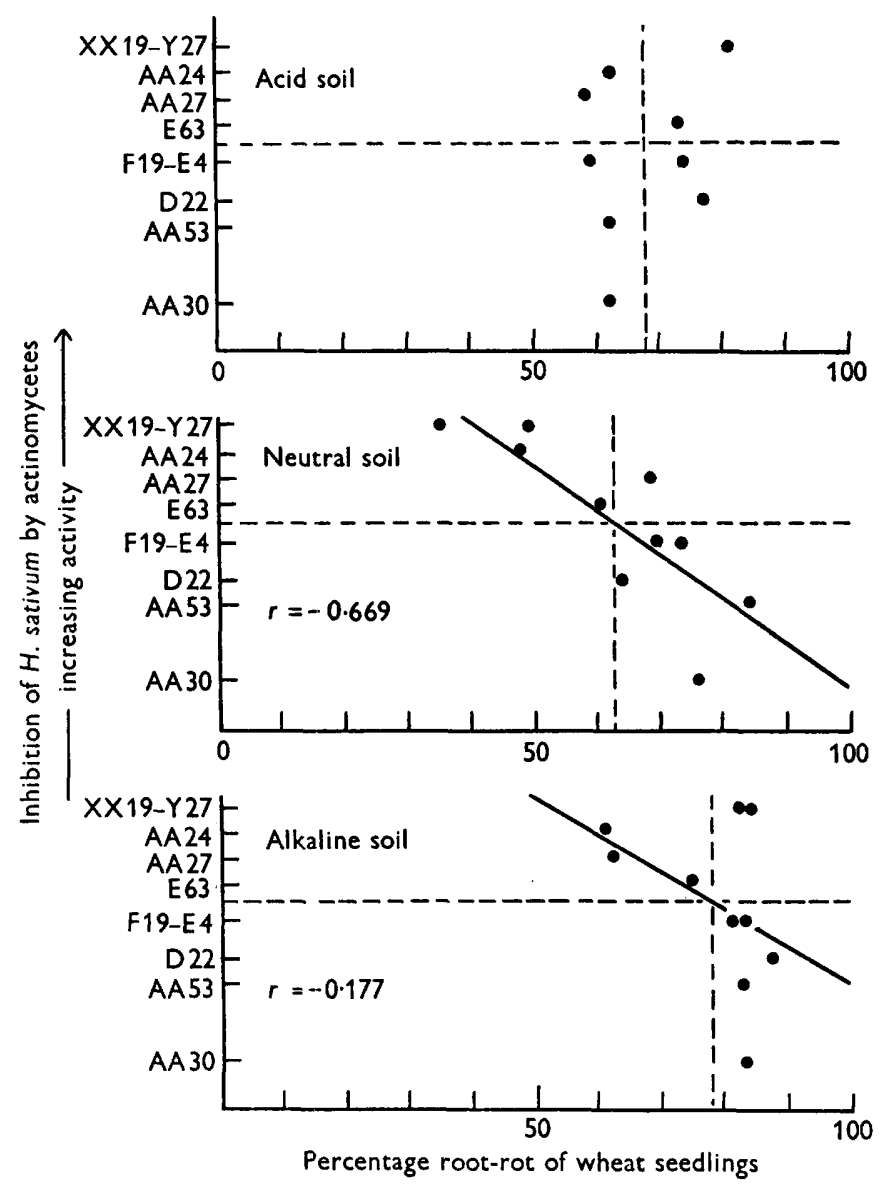

Fig. 1. Scatter diagrams indicating the relationship between the in vitro and in soil antagonism of ten actinomycetes towards Helminthosporium sativum.

supplemented soils (Table 2). The remaining organisms varied in their ability to produce these substances, though rarely did the amounts detected by soil extraction exceed those produced by the aforementioned actinomycetes.

Table 3 indicates that the controlling effects of the organisms D22, E 4, E 63 and F 19 generally fall between those actinomycetes bringing about the greatest reduction in root-rot and those with the least effect. Further comparison shows that the actinomycetes most antagonistic to Helminthosporium sativum in vitro (Table 1) have the greatest controlling effect on the fungus in the neutral soil. This relationship is illustrated in Fig. 1, where the infection ratings 
for the actinomycete treatments are plotted against the inhibition zones of H. sativum produced by the actinomycetes on plates (Table 1 ). When the data are plotted in this manner a pattern is seen in the neutral and alkaline soils. A significant coefficient of correlation was obtained only in the case of the neutral soil data. The scatter of points for the alkaline soil shows a definite tendency to follow the same pattern, but in this soil strains XX19 and Y 27 are poor antagonists. The lack of such a pattern in the acid soil is attributed to the low acid tolerance of the actinomycetes.

\section{DISCUSSION}

In the investigations described, evidence has been produced indicating a relationship between the antagonistic effects displayed by a number of actinomycetes in sterile soil and their antibiotic activity in vitro. This evidence was illustrated by an apparent correlation between the control of root-rot of wheat in sterile soil and the inhibition of the causal fungus by the actinomycetes in Petri dish culture. No relationship was noted between disease control and the ability of these actinomycetes to produce antibiotics in soils as demonstrated by extraction techniques.

Although the ecological significance of antibiotics in soil has often been criticized on similar failures to demonstrate antibiotic production in soil, the possibility remains that these substances are present and active in microenvironments, where a relatively high concentration of antibiotic may be attained in the immediate vicinity of the antagonists, even though the total quantity of antibiotic per gram of soil may be far too small to be detected.

The frequent failure to relate the activity of antagonists in vitro and in soil may thus be due in part to the inadequacy of existing techniques for the detection of antibiotics in soil.

In a preliminary note (Stevenson, 1954) the author has suggested a new and more sensitive technique for demonstration of antibiotic activity in soil and a fuller account of this method will be presented in a later paper.

Contribution no. 395 from the Bacteriology Division, Science Service, Department of Agriculture, Ottawa, Canada.

\section{REFERENCES}

Anwar, A. A. (1949). Factors affecting the survival of Helminthosporium sativum and Fusarium lini in soil. Phytopathology, 39, 1005.

Cooper, V. E. \& Chilton, S. J. P. (1947). Occurrence of Actinomyces antibiotic to Pythium in some sugar cane soils of Louisiana. Phytopathology, 37, 5.

Gottlieb, D. \& SiminofF, P. (1952). The production and role of antibiotics in soil. II. Chloromycetin. Phytopathology, 42, 91.

Gregory, K. F., Allen, O. N., Riker, A. J. \& Peterson, W. H. (1952). Antibiotics as agents for the control of certain damping-off fungi. Amer. J. Bot. 6, 405.

Johnson, L. F. (1952). Control of root-rot of corn under greenhouse conditions by microorganisms antagonistic to Pythium arrhenomanes. Phytopathology, 42, 468. 
Lachance, R. O. \& Perrault, C. (1953). Antagonisme des micro-organismes du sol envers Fusarium oxysporum F. lini, agent de la flétrissure du lin. Canad. J. Bot. 31, 515.

Landerkin, G. B., Smith, J. R. G. \& Lochhead, A. G. (1950). A study of the antibiotic activity of actinomycetes from soils of northern Canada. Canad.J. Res. C, 28, 690.

MCKINNEY, H. H. (1923). Influence of soil temperature and moisture on infection of wheat seedlings by Helminthosporium sativum. J. Agric. Res. 26, 195.

SlagG, C. M. \& Fellows, H. (1947). Effects of certain soil fungi and their byproducts on Ophiobolus graminis. $J$. Agric. Res. 75, 279.

Stevenson, I. L. (1953). Microbiological examination of soils of Arno Atoll. Soil Sci. 75, 225.

Stevenson, I. L. (1954). Antibiotic production by actinomycetes in soil demonstrated by morphological changes induced in Helminthosporium sativum. Nature, Lond., 174, 598.

Thaysen, A. C. (1950). Antibiotics in soil. Nature, Lond., 166, 93.

Waksman, S. A., Horning, E. S., Welsch, M. \& Woodruff, H. B. (1942). Distribution of antagonistic actinomycetes in nature. Soil. Sci. 54, 281.

(Received 12 October 1955) 